\title{
Bacillus spp: una alternativa para la promoción vegetal por dos caminos enzimáticos
}

\author{
Bacillus spp: An alternative for plant promotion by two enzymatic \\ pathways
}

Título abreviado: Bacillus y crecimiento vegetal

Lucía Constanza Corrales Ramírez $M S c^{1}$, Liliana Caycedo Lozano $M S c^{1}$

María Angélica Gómez Méndez ${ }^{2}$, Sonia Julieth Ramos Rojas² ${ }^{2}$ Jessica Natalia Rodríguez Torres ${ }^{2}$

\section{Resumen}

Objetivo. Se realizó una revisión sobre las características de las fitasas y nitrogenasas de Bacillus spp. y sus opciones de uso como alternativa biofertilizante. El género Bacillus es secretor de proteínas y metabolitos eficientes para el control de plagas y enfermedades, promueve el crecimiento vegetal a través de la solubilización de fósforo y la producción de reguladores de crecimiento como el ácido indol acético; así mismo participa en la fijación de nitrógeno cuando hace parte de consorcios microbianos. Como biofertilizante es una opción amigable para el suelo y el ambiente que da respuesta a la necesidad de implementar la agricultura sostenible.

Palabras claves: Bacillus spp., biofertilización, fitasas, nitrogenasas.

\section{Abstract}

Objective. We conducted a review of the characteristics of the phytase and nitrogenase of Bacillus sp. and their potential use as an alternative biological fertilizer. The genus Bacillus is an efficient secretor of proteins and metabolites; to control pests and diseases, promote plant growth through the solubilization of phosphorus and production of growth regulators as acetic indole. Likewise it is involved in nitrogen fixation when it is part of microbial consortia. As biological fertilizer is a friendly option for the soil and the environment that responds to the need to implement sustainable agriculture.

Keywords: Bacillus spp., Biofertilization, phytase, nitrogenase.

1. Docentes investigadoras, Universidad Colegio Mayor de Cundinamarca

2. Estudiantes, Programa de Bacteriología y Laboratorio Clínico, Facultad Ciencias de la Salud, Universidad Colegio Mayor de Cundinamarca.

Bogotá, Colombia. 


\section{Introducción}

El interés creciente de generar alimentos de buena calidad para satisfacer las necesidades de los seres vivos y responder de manera eficiente al objetivo número dos planteado por las Naciones Unidas, para este milenio "poner fin al hambre, lograr la seguridad alimentaria y la mejora de la nutrición y promover la agricultura sostenible" (1), genera la necesidad de aplicar estrategias amigables y sostenibles que mejoren la productividad del suelo y la obtención de productos en óptimas condiciones.

Una de esas estrategias está relacionada con la capacidad fijadora de nitrógeno y solubilizadora de fosfato de Bacillus spp., que ha despertado el interés de investigadores por conocer sobre los procesos metabólicos por medio de los cuales estos microorganismos brindan sus beneficios a la agricultura y al ambiente. La capacidad de estos microorganismos para producir compuestos orgánicos, realizar fijación biológica de nitrógeno (FBN) y solubilizar fosfatos (SF), son actividades que efectúan mediante enzimas como nitrogenasas y fitasas, con un efecto positivo en la promoción del crecimiento vegetal y en el aumento del potencial productivo.

En este sentido, la formulación y el uso de biofertilizantes es una opción que está tomando especial importancia para el mejoramiento de la disponibilidad de nutrientes cuando se aplica a los cultivos (2), por cuanto facilita la fijación biológica de nitrógeno y la solubilización de fosfato, reemplazando positivamente la fertilización química y brindando protección al medio ambiente.

Los microorganismos fijadores de nitrógeno y solubilizadores de fosfato han sido objeto de estudio en la microbiología del suelo y en el desarrollo de productos biológicos comerciales de uso agrícola como los biofertilizantes (3); por tanto, el interés por determinar qué microorganismos contienen las enzimas fitasas y nitrogenasas es vital para la producción agrícola.
La importancia de los biofertilizantes en la industria agrícola se sustenta también en que son una opción amigable para el suelo, ya que el uso excesivo de las tierras fértiles para cultivo y el manejo indiscriminado de fertilizantes químicos desgasta este recurso, y en este caso, los biofertilizantes contribuyen a mitigar el problema de deterioro y/o contaminación ambiental (4) y de esta forma se contribuye con el objetivo número quince de los propuestos para el milenio "proteger, restablecer y promover el uso sostenible de los ecosistemas terrestres, gestionar sosteniblemente los bosques, luchar contra la desertificación, detener e invertir la degradación de las tierras y detener la pérdida de biodiversidad"(1).

En los últimos años, instituciones en Colombia han estudiado y evaluado la acción biofertilizante de microorganismos eficientes que participan en la fijación de nitrógeno y la solubilización de fosfatos. El Instituto Colombiano Agropecuario (ICA) define "un inoculante biológico" como un producto elaborado a partir de una o más cepas de microorganismos benéficos que al aplicarse al suelo o a las semillas promueven el crecimiento vegetal o favorecen el aprovechamiento de los nutrientes (5). De otro lado, estudios como los realizados por la Pontificia Universidad Católica de Chile han demostrado que del $100 \%$ del nitrógeno aplicado en los cultivos, solo del $10 \%$ al $50 \%$ es absorbido por las plantas y del $50 \%$ al $90 \%$ terminan en las aguas subterráneas y superficiales (6).

La mayoría de los microorganismos (bacterias) y plantas (algas y actinomicetos) dependen, por una parte, de la disponibilidad tanto de los grupos $\mathrm{PO}_{4}$ como de la presencia del fósforo inorgánico $(\mathrm{Pi})$, debido a que estos grupos son intermediarios en muchas reacciones en las que se obtiene energía.

De otra parte, el nitrógeno $\left(\mathrm{N}_{2}\right)$ reacciona en forma inorgánica mediante reacciones de reducción en las que cada átomo gana electrones y se 
estabiliza dando origen a iones tales como $\mathrm{NO}_{3}$ (Nitrato) ó $\mathrm{NH}_{4}$ (Amonio) que son los que al tener mayor afinidad se pueden fijar (7). Los fijadores biológicos de nitrógeno y solubilizadores de fosfato ejercen un gran impacto agronómico al ser aplicados en suelos degradados, en donde la microbiota ha sido afectada negativamente por el uso inapropiado de técnicas agrícolas, que seleccionan y/o eliminan organismos de la diversidad, o que afectan su efectividad (8).

La capacidad de Bacillus spp., para formar esporas que permanecen metabólicamente inactivas pero viables bajo condiciones adversas, los hace apropiados para la formulación de productos estables que benefician los cultivos agrícolas a través de mecanismos indirectos. (9)

Este trabajo es una revisión documental que permite proporcionar información sobre las investigaciones realizadas en relación con el uso de las fitasas y nitrogenasas bacterianas en la producción agrícola como biofertilizantes y el beneficio del uso de éstos a nivel ambiental.

\section{Antecedentes}

La producción de biofertilizantes en el mundo inició a finales del siglo XIX, a partir de los estudios realizados por Winogradsky, Waksman y Lipman, pioneros de la microbiología del suelo, al enfocarse en la investigación de microorganismos y su capacidad metabólica para degradar nutrientes importantes en la fertilización del suelo (8).

La fijación del nitrógeno ha sido estudiada desde hace más de 100 años. En 1901, Beijerinck reporta la interacción de microorganismos como Azospirillum, Azotobacter, Bacillus, Clostridium y Klebsiella, que lo fijan por asociación y algunos que forman simbiosis como Rhizobium y Bradyrhizobium (9). En 1907, Ashby realizó estudios con Azotobacter en un medio libre de nitrógeno, medianamente selectivo para bacterias fijadoras de éste, que permite el crecimiento de bacterias fijadoras de nitrógeno y que se conoce como medio Ashby (10).

A comienzos del siglo $\mathrm{XX}$, Smith realizó estudios con el medio Ashby modificado, los cuales se enfocaron en el crecimiento de bacterias como Azotobacter sp., y Azospirillum sp. (11). En la década de 1960 se inician estudios que buscan el desarrollo de nuevas técnicas para determinar la capacidad fijadora de nitrógeno de las bacterias, donde se mencionó por primera vez la presencia de la enzima nitrogenasa como responsable de la capacidad de esta fijación (12). Posteriormente, en 1968, Hardy, Jackson y Burns determinaron la presencia de dicha enzima (13).

La crisis energética de la década de 1970 y los problemas de contaminación debido al uso indiscriminado de fertilizantes nitrogenados impulsaron investigaciones sobre la fijación simbiótica de nitrógeno, centrando la atención sobre el sistema Rhizobium-leguminosa el cual constituye una importante alternativa para la producción agrícola de leguminosas, grano y forrajeras (14).

Seldin y colaboradores en 1984 presentan a Bacillus azotofixans y Bacillus polymyxa como fijadores de nitrógeno (15). Ibarra, en su trabajo de grado menciona que Baldani en el año 1986, dedujo que en $\mathrm{pH}$ alcalino la nitrogenasa reduce su actividad y además afirma que éste también influye en la disponibilidad de nutrientes de manera general para los organismos (16). En 1995, Merrick nombró a los genes que codifican la síntesis de la enzima nitrogenasa como Nif(17), lo que impulsó la realización de métodos moleculares para la identificación de dichos genes en cepas bacterianas.

En 1998 Xie y colaboradores realizaron experimentos con muestras de suelo de las cuales fueron aisladas endosporas generadoras de cepas con ARA (actividad de reducción de acetileno); por lo cual, en dicho estudio se verificó la fijación de nitrógeno en las cepas de Bacillus licheniformis, $B$. 
subtilis, B. cereus, B. pumilus, B. brevis, B. firmus, (18). En 1999, Susan Fisher realizó una revisión de la regulación del metabolismo del Nitrógeno en $B$. subtilis nombrando el sistema Ntr que regula los genes Nif, información que complementa el estudio genético previamente realizado por $\mathrm{Me}$ rrick en 1995 (19).

En el año 2000, Orozco y Martínez afirmaron que los microorganismos que llevan a cabo procesos de fijación del nitrógeno representan aproximadamente el $5 \%$ de la población bacteriana total y se encuentran en superficies de los tejidos radiculares, foliares, suelo y tubérculos de ectomicorrizas (20).

Orhan y colaboradores, en los años 2003 y 2005 , evaluaron dos cepas de Bacillus OSU-142 ( $\mathrm{N}_{2}$-fijación) y $\mathrm{M}_{3}\left(\mathrm{~N}_{2}\right.$-fijación y fosfato solubilización) en un cultivo ecológico de frambuesa en la provincia de Erzurum (Turquía), en el cual se evidenció la promoción del crecimiento vegetal. Los resultados mostraron que la cepa de Bacillus $\mathrm{M}_{3}$ estimuló el crecimiento y la nutrición de la planta de frambuesa en condiciones de crecimiento orgánico (21).

Kloepper y colaboradores en 2004 describen al género Bacillus spp. como promotor de crecimiento en plantas debido a los mecanismos de resistencia sistémica inducida (ISR) que poseen frente a bacterias y hongos patógenos, virus sistémicos y nematodos de la raíz (22).

La fijación biológica de $\mathrm{N}_{2}(\mathrm{FBN})$ es el primer paso del ciclo del $\mathrm{N}_{2}$ que va desde la atmósfera hasta la biósfera. Estudios realizados en Brasil por Beneduzi y colaboradores en 2008 reportan cepas del género Bacillus spp., aisladas de siete zonas de producción de trigo, como fijadoras de nitrógeno, donde además se observó la producción de compuestos indólicos: indol-3-acético-ácido (IAA) y ácido indolpirúvico (IPyA). La identificación se realizó mediante secuenciación del gen $16 \mathrm{~S}$ rRNA de las cepas, que podrían ser útiles en la formulación de nuevos inoculantes para la mejora de cultivos, ya que demostraron un aumento significativo del follaje en plantas de trigo (23).

Acuña y colaboradores en 2010 comprobaron que en suelos contaminados con hidrocarburos, la fijación biológica de nitrógeno (FBN) es difícil debido a que la disponibilidad de nitrógeno $\left(\mathrm{N}_{2}\right)$ es limitada para los microorganismos, lo cual dificulta su desarrollo. Se evidenció también que la baja disponibilidad y solubilidad en el agua conlleva a la disminución en la fijación del nitrógeno (24).

De otro lado, Arthur Harden. y William Young, en 1905 expusieron la importancia del fósforo en las células, y en los estudios realizados a través de lo $s$ años, se ha demostrado que el fósforo es el segundo nutriente más importante para el desarrollo y el crecimiento de los microorganismos presentes en el suelo después del nitrógeno. Hace parte de los ácidos nucleicos, del ATP y de otras moléculas que tienen el ion fosfato (PO4), demostrando que contribuyen al aumento de la biomasa, las reacciones de respiración, la obtención de nutrientes y biosíntesis de macromoléculas, entre otras, como lo señalan Sanyal y De Data (25).

En 1994, Richardson, en su estudio sobre los microorganismos del suelo y la disponibilidad del fósforo, señala que la presencia de este elemento para las plantas, microorganismos y otros seres vivos, tiene especial importancia ya que se encuentra en cantidades reducidas y en formas insolubles, a pesar de suministrarse en forma de fertilizantes (26).

Shin y colaboradores, en 2001, señalan en el estudio realizado sobre el mecanismo catalítico y las propiedades de las fitasas que existen reacciones de fosforilación y desfosforilación fundamentales para la vida que son catalizadas por enzimas y utilizadas para almacenar y recuperar energía química, facilitar las seńales de transducción y pro- 
mover el metabolismo, en las cuales participan microorganismos del suelo mediante procesos de mineralización del fósforo orgánico a través de actividades enzimáticas (27).

Wakelin y colaboradores, en 2004, infieren que mediante la actividad bioquímica de microorganismos en el suelo rizosférico se puede aumentar la solubilidad del fósforo, demostrado la actividad enzimática que realizan especies de bacterias y hongos, lo cual se traduce en el incremento de la disponibilidad del fósforo cuando existe buena actividad microbiana en el suelo (28).

Fernández y Rodríguez, en 2005, describen la importancia del fósforo en la nutrición vegetal y el papel de los microorganismos solubilizadores en la adquisición de éste, de tal forma que los microorganismos se convierten en los principales protagonistas para el desarrollo de biofertilizantes (29). De la misma manera, en 2005, Oberson y Joner confirman que los microorganismos que influyen en la transformación del fósforo con la consecuente disponibilidad en el suelo, involucran a toda la microbiota que está entre 0 y $100 \mu \mathrm{m}$ de diámetro, siendo las bacterias los microorganismos de este tamaño más numerosos presentes en términos de biomasa (30).

Las bacterias solubilizadoras de fosfato son protagonistas del aumento de la disponibilidad del fósforo (P) en el suelo, ya que tienen la capacidad de intervenir en los procesos de fijación de éste, demostrando que su empleo en diversos cultivos favorece el rendimiento de las cosechas y mejora la fertilidad del suelo (31). Estudios realizados por Khan y colaboradores en 2007 (32) y Zaidi y colaboradores en 2009 (33), en los cuales ensayan con Bacillus, Pseudomonas, E.coli y Aspergillus, ponen en evidencia la capacidad solubilizadora de fosfatos.

De otro lado, diferentes investigaciones describen las fitasas como endoenzimas producidas por bacterias, las cuales tienen mayor afinidad reacti- va por el ácido fítico $\left(\mathrm{C}_{6} \mathrm{H}_{18} \mathrm{O}_{24} \mathrm{P}_{6}\right)$ como sustrato para generar una forma asimilable del fósforo $(\mathrm{P})$ (34). Los avances biotecnológicos han permitido la caracterización de muchas fitasas provenientes de microorganismos, como Aerobacter aerogenes, tal como lo describe Greaves y colaboradores en 1967 (35); Pseudomonas sp., por Irving y Cosgrove en 1971 (36); Bacillus subtilis por Powar y Jagannathan en 1982 (37), y E. coli por Greiner y colaboradores en 1993 (38), también se encuentra el reporte de algunas especies de hongos como Aspergillus flavus y Penicillium spp., por Shieh y Ware en 1968 (39); y levaduras como Candida sp. por Rojas en 2009 (40).

Estudios de laboratorio realizados por Hayes y colaboradores en 2000, y posteriormente por $\mathrm{Ri}$ chardson en 2001, demostraron que la inoculación de microorganismos con actividad fitasa o la adición de fitasas microbianas purificadas a las raíces de plantas, incrementan el fósforo suministrado por el fitato, permitiéndole solubilizarse para su absorción, lo cual contribuye en la nutrición de las plantas y se observa en las condiciones de crecimiento de las mismas (41).

Mediante técnicas moleculares, los genes que codifican la actividad de fitasas (Phy) han sido clonados a partir de bacterias, hongos y plantas. También se han podido conocer algunas características de éstos genes relacionados con la estabilidad a temperaturas altas; como es el caso de las de Bacillus sp. DS11 y Bacillus subtilis VVT E-68013, que son térmicamente estables a determinados $\mathrm{pH}$, mientras que los genes de $B$. subtilis $y B$. licheniformis actúan mejor a $\mathrm{pH}$ neutro (34).

Esto mismo ha pasado con los genes de nitrogenasas (Nif), los cuales mediante técnicas de biología molecular también han sido aislados e introducidos en diferentes plantas de interés agrícola (42). Recientemente, la expresión del gen nifH ha sido estudiada mediante PCR con transcripción inversa (RT-PCR) para evaluar la actividad de fijación de nitrógeno de la bacteria endofita Azoar- 
cus spp, de las comunidades microbianas fijadoras de nitrógeno en el intestino de termitas, del suelo, y del agua marina (34). Por otro lado, gracias al desarrollo de nuevas investigaciones se ha logrado identificar la actividad de fitasas en diferentes especies bacterianas, bajo estimulo in vitro (43).

En aislamientos obtenidos a partir de Bacillus subtilis, Aspergillus niger y Escherichia coli se ha evidenciado que tienen actividad enzimática fosfatasa como las BPPs. Otras enzimas como las fosfatasas ácidas púrpura (Purple acidic phosphatases "PAP") o fitasas cisteínicas, son comunes en microorganismos, plantas y mamíferos. Estas enzimas tienen como cofactores iones metálicos y fueron encontradas en bacterias anaeróbicas como Selenomonas ruminantium del rumen, y de acuerdo con su mecanismo catalítico se sugiere que presentan la secuencia conservada de HCXXGXXR (T/S) en su sitio activo. Las fitasas más comúnmente usadas en la industria son microbianas; las de hongos filamentosos son extracelulares y las bacterianas son intracelulares a excepción de las del género Bacillus, y las de levaduras que son mixtas (44).

\section{Nitrógeno}

El nitrógeno es uno de los elementos más abundantes en la naturaleza. En su forma molecular $\left(\mathrm{N}_{2}\right)$ se calcula que en el planeta hay más de 60.000 billones de toneladas de nitrógeno, de los cuales aproximadamente el $94 \%$ está ubicado en la corteza terrestre; del 6\% restante, el 99,86\% se halla en la atmósfera y el $0,04 \%$ en los organismos vivos, suelos y aguas en forma de compuestos orgánicos e inorgánicos, como macronutriente que los organismos utilizan para sintetizar proteínas (45).

Se han descrito algunas especies de bacterias y algas capaces de fijar Nitrógeno para formar amoníaco $\left(\mathrm{NH}_{3}\right)$, el cual se incorpora al suelo donde bacterias nitrificantes lo oxidan a nitritos $\left(\mathrm{NO}_{2}\right.$ 1) y posteriormente a nitratos $\left(\mathrm{NO}_{3}^{-1}\right)$, proceso conocido como nitrificación. La mayoría de los microorganismos y las plantas son dependientes de este elemento en forma inorgánica, es decir, en forma de iones de nitratos $\left(\mathrm{NO}_{3}^{-1}\right)$ o de amonio $\left(\mathrm{NH}_{4}^{+1}\right)$, o en algunas ocasiones como moléculas sencillas. Por el contrario, los animales necesitan del nitrógeno orgánico, es decir, formando parte de compuestos como aminas, amidas o aminoácidos, que son obtenidos de forma directa o indirecta de las plantas (45).

\section{Nitrógeno y plantas}

La fuente de nitrógeno para las plantas está constituida por el amonio y el nitrato disuelto en el suelo ( $\mathrm{N}$ asimilable), sin embargo, el 98\% del $\mathrm{N}$ presente en el suelo está combinado en moléculas orgánicas y por lo tanto no está disponible para la nutrición vegetal. Entre el 1 y 3\% de éste, es mineralizado en un ańo por los procesos biológicos denominados amonificación y nitrificación. La otra parte se volatiliza por procesos de desnitrificación como $\mathrm{NH}_{3}$, $\mathrm{NO}$ y $\mathrm{N}_{2} \mathrm{O}$, mientras que el compuesto $\mathrm{NO}_{3}$ se precipita al no ser absorbido por suelos arcillosos, evento que evita la captación inmediata por los vegetales o microorganismos (45).

\section{Ciclo biogeoquímico del Nitrógeno}

El ciclo del nitrógeno está compuesto por 5 procesos que se definen como mineralización, nitrificación, desnitrificación, asimilación y fijación. La asimilación es el único proceso que no es realizado por las bacterias (45). 


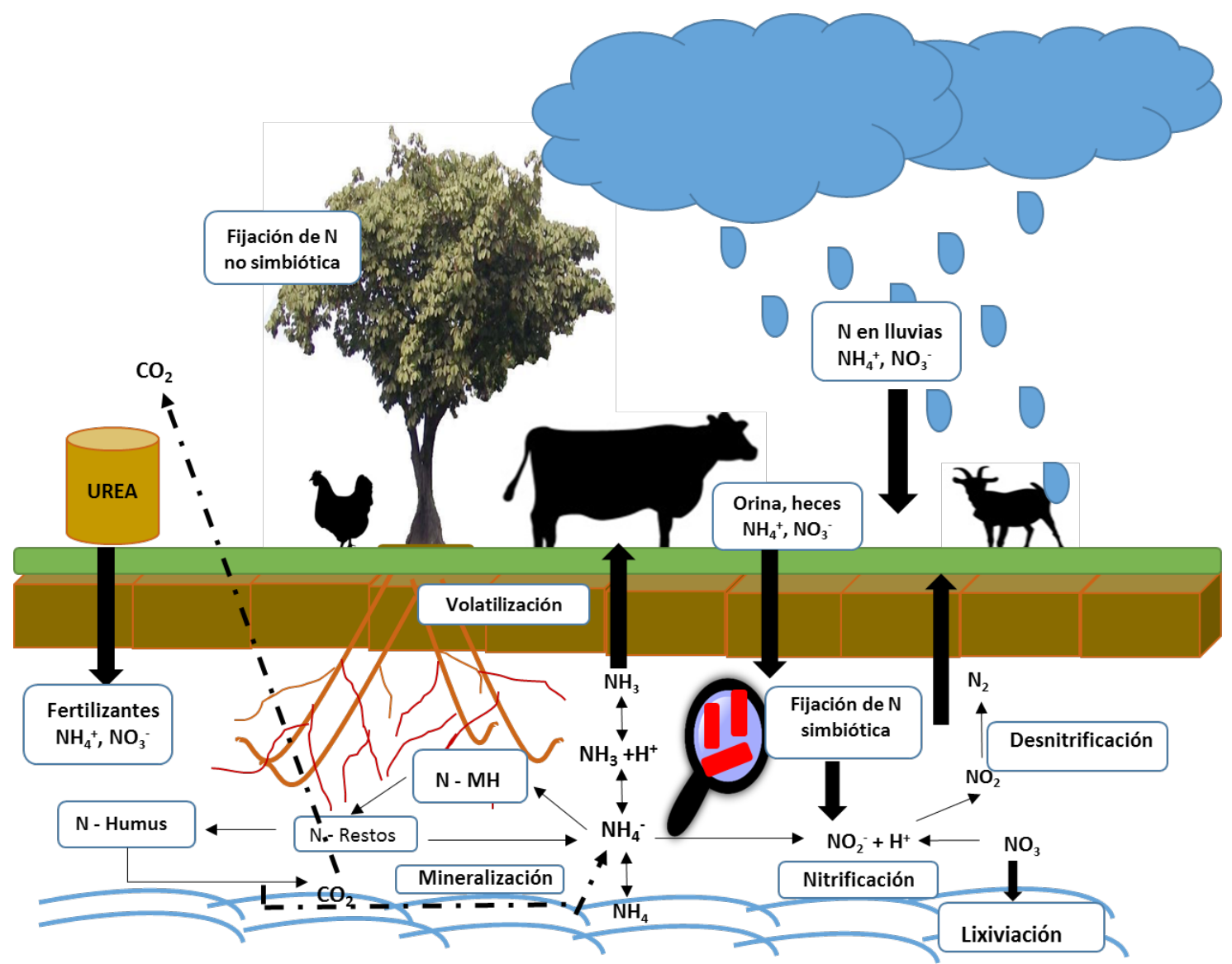

Figura 1. Ciclo del nitrógeno. Fuente: L. C. Corrales 2016. (46)

Como se estableció anteriormente, el nitrógeno molecular $\left(\mathrm{N}_{2}\right)$, está presente en la atmósfera en un $80 \%$ y es considerado una molécula casi inerte debido al triple enlace que presenta entre sus dos átomos de nitrógeno. Esta unión no le permite ser asimilado directamente por las plantas y necesita ser fijado previamente por microorganismos que lo liberan transformándolo en amonio o nitratos que son asimilados por la planta (45).

Estudios muestran que la temperatura es inversa al contenido de nitrógeno y materia orgánica en el suelo; es decir, al incrementar la energía cinética del medio, disminuye la cantidad de nitrógeno presente en el suelo, mientras que, al incrementar la pluviosidad aumenta la vegetación y por ende la concentración de nitrógeno (47). De otra parte, con relación al tipo de suelo, este influye en la cantidad de nitrógeno presente. Los suelos arcillosos son los que presentan este elemento en mayor cantidad, en comparación con los suelos arenosos y limosos (45).

\section{Transformaciones del nitrógeno en el suelo}

El nitrógeno que entra en el suelo está sujeto a muchas transformaciones. El nitrógeno de las fuentes orgánicas pasa a formar parte de la materia orgánica del suelo y una parte de éste se convierte en nitrógeno inorgánico a través del proceso llamado mineralización. El suelo contiene: amonio $\left(\mathrm{NH}_{4}^{+1}\right)$ y nitrato $\left(\mathrm{NO}_{3}^{-1}\right)$. $\mathrm{El} \mathrm{NH}_{4}^{+1}$ es atraído electrostáticamente por las cargas aniónicas y las sustancias coloidales del suelo (arcillas y humus) a través de reacciones iónicas. Por otro lado, el $\mathrm{NO}_{3}^{-1}$, se solubiliza en el agua del suelo y no es retenido por las cargas aniónicas. $\mathrm{El} \mathrm{NH}_{4}^{+1}$ y el $\mathrm{NO}_{3}^{-1}$ son las únicas formas de Nitrogeno que pueden ser absorbidas por las raíces de las plantas $(1,48)$. 


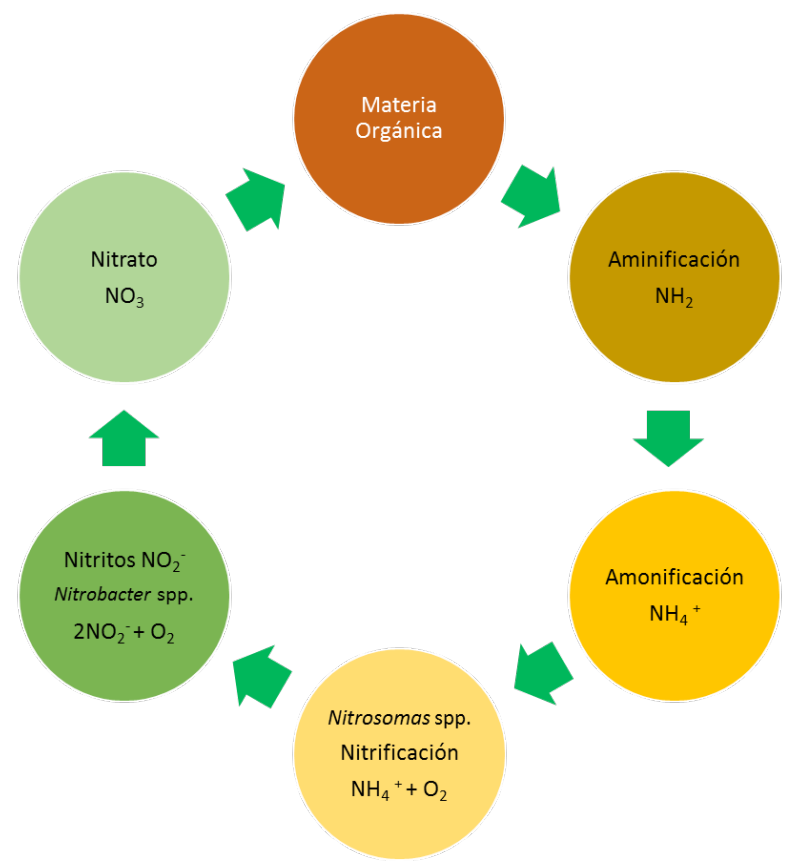

Figura 2. Transformaciones del nitrógeno en el suelo . Fuente: L. C. Corrales 2016 (49)

\section{El nitrógeno en fertilizantes para la planta}

El nitrógeno orgánico se encuentra en forma de materia orgánica, pero no es aprovechable por las plantas. El nitrógeno inorgánico se encuentra en forma $\mathrm{NH}_{4}^{+}{ }^{+} \mathrm{NO}_{3}{ }^{-}$como fertilizante inorgánico, como se observa en la Tabla 1.

Tabla 1. Forma en que se encuentra el nitrógeno en los fertilizantes.

Fuente: las autoras.

\begin{tabular}{|l|l|}
\hline Fertilizante inorgánico & $\begin{array}{l}\text { Formas en que } \\
\text { se encuentra el } \\
\text { nitrógeno }\end{array}$ \\
\hline Úrea $\left(\mathrm{CH}_{4} \mathrm{~N}_{2} 0\right)$ & $\begin{array}{l}\text { Aminas que se } \\
\text { convierten en } \\
\mathrm{NH}_{4}^{+}\end{array}$ \\
\hline Sulfato de amonio $\left(\mathrm{NH}_{4}\right)_{2} \mathrm{SO}_{4}$ & $\mathrm{NH}_{4}^{+}$ \\
\hline $\begin{array}{l}\text { Fosfato de amonio }-\mathrm{Fosfato}_{4} \\
\text { ácido de amonio }\left(\mathrm{NH}_{4}\right)_{3} \mathrm{PO}_{4} \\
\left(\mathrm{NH}_{4}\right)_{2} \mathrm{HPO}_{4}\end{array}$ & $\mathrm{NH}_{4}^{+}$ \\
\hline Nitrato de Calcio $\mathrm{Ca}\left(\mathrm{NO}_{3}\right)_{2}$ & $\mathrm{NO}_{3}^{-}$ \\
\hline Nitrato de amonio $\mathrm{NH}_{4} \mathrm{NO}_{3}$ & $\mathrm{NO}_{3}^{-}+\mathrm{NH}_{4}^{+}$ \\
\hline Nitrofoska & $\mathrm{NO}_{3}^{-}+\mathrm{NH}_{4}^{+}$ \\
\hline
\end{tabular}

\section{Fósforo}

El fósforo $(\mathrm{P})$ es uno de los macronutrientes más importantes encontrados en la naturaleza y como elemento químico es absolutamente necesario, porque participa en el crecimiento de las plantas y en procesos metabólicos como la fotosíntesis, la transferencia de energía y la degradación de carbohidratos. "El fósforo en los vegetales se encuentra de forma inorgánica en pequeña proporción y la mayor parte se encuentra unido al ácido fítico que contiene aproximadamente un $28 \%$ en forma de radicales de ácido fosfórico. Estos radicales tienen afinidad por diversos cationes como: $\mathrm{Fe}^{+3}$, $\mathrm{Ca}^{+2}, \mathrm{Cu}^{+}, \mathrm{Zn}^{+2}$, citados en orden decreciente de afinidad" (50)

El fósforo como constituyente de sustancias orgánicas da origen a fracciones lábiles y resistentes a la mineralización, cuyo componente orgánico más importante es la biomasa microbiana que degrada y libera diferentes compuestos fosfatados. El fósforo orgánico se genera a partir de restos vegetales y animales, este tipo de fósforo es absor- 
bido en mayor cantidad en suelos arcillosos (50). El fósforo inorgánico, está conformado por diferentes minerales que liberan fósforo por meteorización, es decir de forma muy lenta. Las formas de fosfato inorgánico, son de menor solubilidad en comparación al fósforo orgánico (2)

\section{Fósforo y plantas}

El fósforo es absorbido por las plantas a través de su raíz y las capas externas de las células del sistema radicular. Se absorbe principalmente como ión de ortofosfato primario (Fosfato diácido $\mathrm{H}_{2} \mathrm{PO}_{4}^{-}$) o también por medio iones de fosfato secundario (Fosfato ácido - $\mathrm{HPO}_{4}=$ ) Esta última forma incrementa los niveles de $\mathrm{pH}$. Una vez fijado al sistema radicular, el fósforo tiende a distribuirse por toda la planta a través de reacciones químicas que le permiten incorporarse a compuestos orgánicos donde queda disponible para otros tipos de reacciones. No obstante, en el suelo más del $90 \%$ de éste pasa a forma insoluble, es decir no disponible, por eso es importante resaltar que la biodisponibilidad de este elemento es vital en reacciones energéticas, procesos fotosintéticos, transferencia genética y transporte de nutrientes en estos organismos (2).

El fósforo también interviene en el proceso de fotosíntesis:

\section{$6 \mathrm{CO}_{2}+12 \mathrm{H}_{2} \mathrm{O}->>>\mathrm{C}_{6} \mathrm{H}_{12} \mathrm{O}_{6}+6 \mathrm{O}_{2}$ Reacción Neta}

Esta reacción ocurre en dos etapas:

Fase luminica: la absorción de la energía solar por las moléculas de clorofila propicia un transporte de electrones y aunado al gradiente de protones se produce adenosin trifosfato (ATP). Durante este proceso, la molécula de agua se escinde y se libera $\mathrm{O}_{2}$, los electrones son absorbidos por el NADP+ con la consecuente formación del NADPH.

Fase oscura: es una ruta metabólica que se sucede en los cloroplastos. En este ciclo, se utiliza el
ATP (Energía Química) y el NADPH obtenidos en la fase lumínica, con el fin de reducir moléculas inorgánicas de $\mathrm{CO}_{2}, \mathrm{NO}_{3}$ y $\mathrm{SO}_{4}$ en sustancias reducidas de carácter orgánico que propician la construcción de moléculas más complejas. De manera general, se puede establecer que en ésta fase ocurre lo siguiente:

- Fijación del $\mathrm{CO}_{2}$ a la ribulosa 1,5 difosfato y obtención de dos moléculas de ácido fosfoglicérico

- Reducción del ácido fosfoglicérico a gliceraldehído-3-Fosfato con la intervención del ATP y el NADPH.

En estos resultados generales de la reacción se obtienen moléculas que se constituyen en fuentes de energía química para diversas reacciones en la planta que conllevan a la liberación de oxígeno (51). De otra parte, los fosfatos constituyen los ácidos nucleicos y los fosfolípidos esenciales en la división celular, fundamentales para el desarrollo de tejidos meristemáticos (52).

\section{Mineralización de fósforo}

El fósforo es abundante en los suelos, contribuye a la nutrición y desarrollo de los seres vivos debido a los procesos de hidrólisis y liberación de fosfatos libres (53). Las fosfatasas son enzimas catalizadas a medida que se van liberando de acuerdo a los procesos orgánicos naturales (54). De estas enzimas las más estudiadas son las fosfomonoestereasas, grupo enzimático que actúa sobre compuestos fosfatados de bajo peso molecular con enlaces monoéster, incluyendo mononucleótidos, fosfatos de azúcar y polifosfatos. Estas enzimas no pueden iniciar el clivaje del ácido fítico (myo-inositolhexaquifosfato) aunque el proceso de catalización se puede llevar a cabo por medio de la hidrólisis de inositoles fosfato de orden menor (55).

En un estudio realizado en 2002 se menciona que estimar la cantidad de fósforo orgánico disponible a través de la mineralización es importante, considerando los cambios en el fosfóro orgáni- 
co extraído con $\mathrm{NaHCO}_{3}$ como una medida de éste elemento potencialmente mineralizable. Sin embargo, los cambios netos en fósforo orgánico son generalmente pequeños en relación al tamaño de los reservorios totales, determinando que la variedad climática de los suelos influye sobre la actividad microbiana, ocasionando un aumento significativo de la mineralización neta del P orgánico (56).

\section{Ciclo del fósforo}

El ciclo del fósforo en el suelo, involucra tanto a la biomasa microbiana, como a la materia orgánica e inorgánica, incluyendo diferentes fuentes de fósforo, por eso este ciclo es catalogado como complejo y dinámico. Las fuentes de fósforo encontradas se dividen en fósforo inorgánico disponible (Pi), fósforo orgánico, fósforo absorbido, y fósforo mineral primario (57).

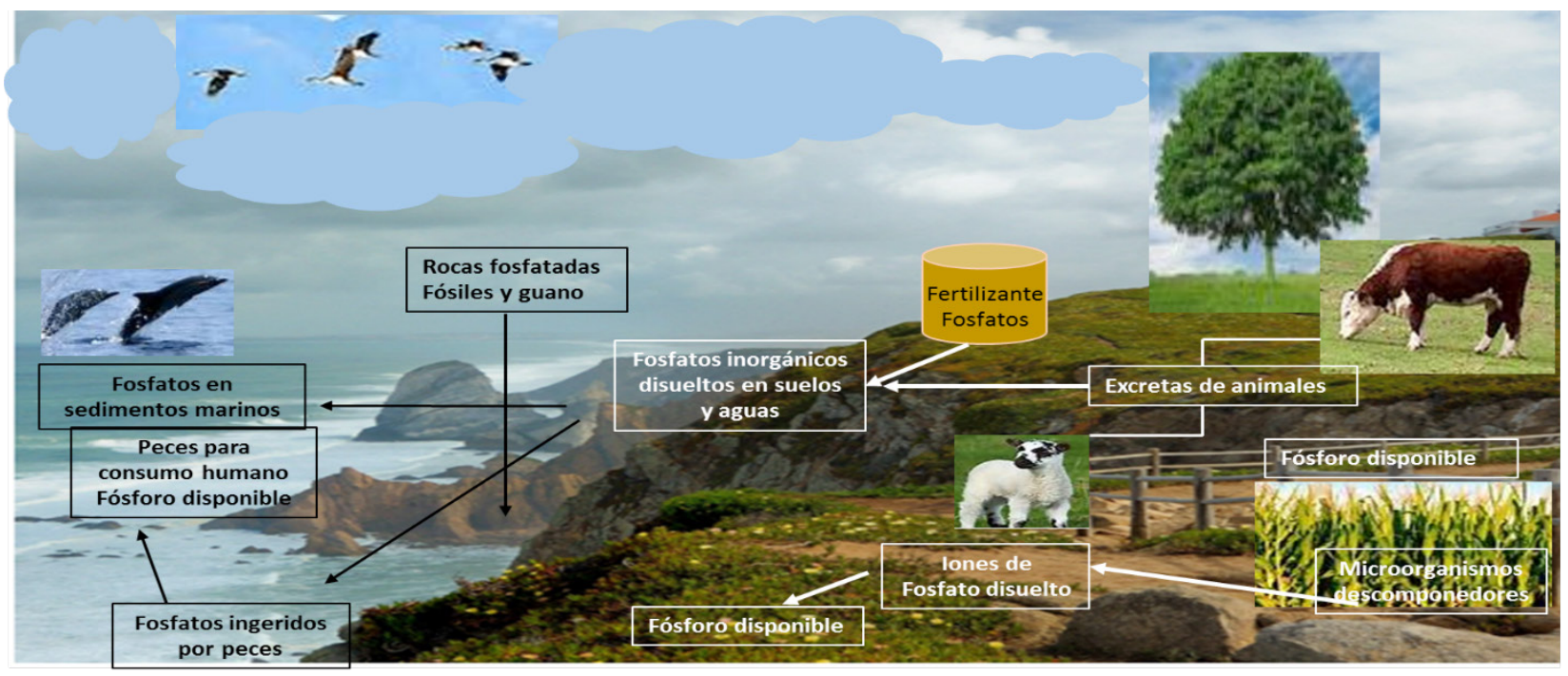

Figura 2. Ciclo de fósforo. Fuente: L. C. Corrales 2016 (58)

El fósforo se mueve lentamente desde los depósitos de fosfato en la tierra y los sedimentos de los mares a los organismos vivos, para luego regresar a la tierra y al océano. El suelo contiene minerales ricos en fósforo, los cuales permanecen ahí por largos periodos de tiempo y lentamente el fósforo se hace disponible para las plantas, gracias a las variaciones en las constantes de solubilidad de los diferentes minerales. Cuando ocurre el fenómeno de precipitación, el fósforo se comporta como un nutriente no disponible; y la reacción ocurre entre el Pi y elementos metálicos tales como calcio, hierro y aluminio formando sales de fosfato (47).

Microorganismos fijadores de nitrógeno y solubilizadores de fosfato

Los microorganismos fijadores de nitrógeno y solubilizadores de fosfato requieren fuentes quí- micas y naturales de energía. Éstos mediante sus procesos metabólicos generan enzimas que catalizan la ruptura de los enlaces del nitrógeno y del ácido fítico constituyéndose en precursores de reacciones químicas. Las bacterias intermediadoras de vida libre que participan en estos procesos son: Bacillus spp., Clostridium spp., Klebsiella spp., Pseudomonas spp., Enterobacter spp., Azotobacter spp., y Azospirillum spp., las que han sido aísladas de la rizosfera, donde el número de microorganismos diazótrofos es generalmente mayor por la liberación y concentración disponible de nutrientes en forma de compuestos orgánicos (57).

Los microorganismos solubilizadores de fósforo conocidos como PSM hacen parte del grupo de microorganismos promotores de crecimiento vegetal (PGPM), que suplen las necesidades de 
fósforo en las plantas a través de la solubilización, usando mecanismos como la liberación de ácidos orgánicos, gradientes de protones y mecanismos de catálisis (acción de las fosfatasas). Dentro del grupo de bacterias solubilizadoras de fósforo más eficientes, se han reportado los géneros Bacillus spp., Pseudomonas spp., Rhizobium spp., Burkholderia spp., Achromobacter spp., Agrobacterium spp., Microccocus spp., Aerobacter spp., Azotobacter spp. y Erwinia spp., y hongos saprófitos, como Aspergillus niger, Penicillium bilaii, Penicillium simplicissimun, Trichoderma harzianum, y Cladosporium herbarum (9).
Cuando el fósforo ya ha sido solubilizado por la intervención de PSM, puede reaccionar de nuevo con elementos metálicos del suelo. De esta manera, la dinámica microbiana seguirá siendo una solución viable a los problemas de baja disponibilidad de fosfato en suelos (59).

En la Tabla 2, se observan las bacterias que realizan actividad enzimática nitrogenasa o fitasa y su mecanismo de acción.

Tabla 1. Microorganismos con actividad enzimática Nitrogenasa o Fitasas. Fuente: Las autoras.

\begin{tabular}{|c|c|c|c|}
\hline Microorganismos & Mecanismo de acción & $\begin{array}{l}\text { Actividad } \\
\text { enzimática } \\
\text { Nitrogenasa }\end{array}$ & $\begin{array}{l}\text { Actividad } \\
\text { enzimática } \\
\text { Fitasas }\end{array}$ \\
\hline Azotobacter spp. & $\begin{array}{l}\text { - pH: óptimo para crecer cuando fijan nitrógeno es } 7.0 \\
\text { - } 7.5 \text {. } \\
\text { - Produce gran cantidad de exopolisacáridos. } \\
\text { - Posee mecanismos de protección de la nitrogenasa: fija } \\
\text { nitrógeno en aerobiosis. } \\
\text { - Forma estructuras de resistencia (heterocistes) a la } \\
\text { desecación y a la radiación. }\end{array}$ & $\mathrm{X}$ & \\
\hline Rhizobium spp. & $\begin{array}{l}\text { - Síntesis de auxinas el ácido indol-acético (AIA). } \\
\text { - Alivia efectos de salinidad y acidificación. } \\
\text { - Inducen resistencia a estrés. }\end{array}$ & $\mathrm{X}$ & \\
\hline Azospirillum spp. & - Producción de fitohormonas estimuladoras. & $\mathrm{X}$ & \\
\hline Acinetobacter spp. & $\begin{array}{l}\text {-Producción de sideróforos. } \\
\text { - Síntesis de fitohormonas. }\end{array}$ & & $\mathrm{X}$ \\
\hline Pseudomonas spp. & $\begin{array}{l}\text { - Liberan ácido indol-acético (AIA) citoquininas en la } \\
\text { rizosfera de las plantas. } \\
\text { - Efecto estimulador del crecimiento. } \\
\text { - Control de patógenos sintetizando moléculas } \\
\text { antifúngicas. } \\
\text { - Producción de sideróforos. } \\
\text { - Síntesis de proteasa lítica, inhibe hongos. }\end{array}$ & & $\mathrm{X}$ \\
\hline Serratia spp. & $\begin{array}{l}\text { - Alivia efectos de salinidad y acidificación. } \\
\text { - Síntesis de fitohormonas. } \\
\text { - Producción de sideróforos. }\end{array}$ & & $\mathrm{X}$ \\
\hline Bacillus spp. & $\begin{array}{l}\text { - Liberan ácido indol-acético (AIA) o citoquininas en la } \\
\text { rizosfera de las plantas } \\
\text { - Efecto estimulador del crecimiento. } \\
\text { - Biocontrolador. }\end{array}$ & & $\mathrm{X}$ \\
\hline
\end{tabular}




\section{Género Bacillus}

El género Bacillus fue descrito por primera vez por Ferdinand Julius Cohn entre 1870 y 1880, su heterogeneidad en la fisiología ecológica dificulta su clasificación genética o su generalización (60). Mediante técnicas moleculares para el estudio del RNAr 16s, se ha logrado subdividir en cuatro grupos: el primer grupo se conoce como Bacillus senso stricto donde encontramos el Bacillus subtilis, el segundo grupo Bacillus sensu lato que incluye principalmente $B$. anthracis, $B$. thuringiensis y $B$. cereus, finalmente se han descrito dos grupos más con nuevas especies, destacando a $B$. horti, B. carboniphilus, B. chitinolycus, y B.infernus, entre otros (61).

Bacillus es un género de interés, dado que aporta un amplio perfil de diversidad fisiológica (acidofilia, alcalofilia, psicrofilia, termofilia y parasitismo), virtud que es otorgada por la formación de su espora, cualidad que le permite estar en diferentes hábitats tanto acuáticos como terrestres (61).

La interacción del género Bacillus con el hábitat terrestre puede ocurrir de forma directa o indirecta. La forma directa, cuando actúa como agente rizosférico, el cual tiene la capacidad de degradar sustratos derivados de la fauna, la flora y los compuestos de origen orgánico como los hidrocarburos; promueve la producción de antibióticos, promoción de crecimiento vegetal y los procesos de fijación de nitrógeno y solubilización de fosfatos y de forma indirecta, cuando actúa en la producción de sustancias antagonistas de patógenos o induciendo mecanismos de resistencia (62).

\section{Nitrogenasas de Bacillus}

Estas enzimas reducen la molécula de $\mathrm{N}_{2}$ y constan de dos componentes:

a) Componente I o dinitrogenasa: posee un cofactor que es una asociación entre hierro y molibdeno (FeMo) también llamado heterotetrámero, el cual forma parte del centro activo. La proteína $\mathrm{Fe}-\mathrm{M}$, donde el metal $(\mathrm{M})$ puede ser molibdeno, vanadio o hierro, es un tetrámero $\alpha_{2} \beta_{2}$ constituido por 30 átomos de hierro y dos del metal correspondiente, distribuidos en dos tipos de cúmulos: los empaques cúbicos o tipo "P" (8 Fe, $7 \mathrm{~S}_{2}$ ) y el cofactor Fe-M (63). Esta proteína es inactivada por el oxígeno.

b) Componente II o dinitrogenasa reductasa , la cual pasa los electrones al componente I, con consumo de ATP y el componente I cede posteriormente los electrones al sustrato. De la enzima hace parte el cofactor, que es donde se lleva a cabo la reacción con el sustrato. Puede estar asociado de manera permanente a la enzima, conociéndose entonces como grupos prostéticos, o de forma transitoria, denominándose co-sustratos. (63). Como resultado, las nitrogenasas, simultáneo a la reducción de nitrógeno molecular, efectúan procesos de fijación de nitrógeno convirtiéndolo en amoniaco fácilmente asimilable por las plantas.

Para formar la enzima activa nitrogenasa se requiere una molécula del componente I y dos moléculas del componente II.

De acuerdo con el metal representativo en el centro activo se distinguen tres nitrogenasas, cuya diferencia radica en el catión hexacoordinado presente en el cofactor Fe-M:

1. Nitrogenasa de Mo. La más abundante, encontrada en todas las especies que contienen la enzima nitrogenasa.

2. Nitrogenasa de V. La segunda en abundancia y en ser descubierta. Se encuentra en Azotobacter vinelandii.

3. Nitrogenasa de Fe. Se encuentra en una proporción mucho menor a las anteriores. Aislada de Rhodobacter capsulat. (64)

\section{Fitasas de Bacillus}

Con relación a las fitasas, se puede establecer que son enzimas pertenecientes a la subfamilia de las 
fosfatasas. Estas constituyen un conjunto diferenciado de enzimas que se clasifican en fosfatasas alcalinas, ácidas de alto y bajo peso molecular y fosfatasas-proteína, las cuales se diferencian por los valores de $\mathrm{pH}$ óptimos en los que catalizan las hidrólisis de los enlaces éster, afinidad por los cationes metálicos, especificidad por los substratos $\mathrm{y}$, posiblemente, por los mecanismos de reacción (65).

Las fitasas (myo-inositol hexafosfato hidrolasas) se encuentran de forma común en la naturaleza y pueden ser de origen microbiano, vegetal o animal. Un reciente grupo de proteínas fosfatasas tirosínicas que degrada ácido fitico (AF) se añadió a la lista de fitasas (Protein Tyrosin Phosphatases, "PTP"). Además, se han aislado (PAP's 5-fitasas) desde especies vegetales como alfalfa, porotos, arvejas, y del polen de la Lilia; y las de origen animal como las Selenomonas ruminantium, capaces de hidrolizar ácido fítico a ortofosfato inorgánico y una serie de ésteres fosfóricos menores liberando finalmente el myo-inositol (66).

La IUPAC-IUB reconoce la 3-fitasa y la 6-fitasa, denominadas así por las posiciones en las que se inicia la reacción de hidrólisis sobre el enlace éster. La 3-fitasa se encuentra en animales y microorga- nismos mientras que la 6-fitasa está presente en vegetales. Existen evidencias de que las fitasas pueden incrementar significativamente la utilización y la disponibilidad de fósforo proveniente del ácido fítico y supone una reducción en la excreción de fósforo (67).

Estructuralmente las fitasas son enzimas que se clasifican como fosfohidrolasas, las cuales intervienen en la hidrólisis del ácido fítico (hexafosfato de inositol) o fitatos. Las fitasas bacterianas de acuerdo con los mecanismos catalíticos y la especificidad de hidrólisis se pueden categorizar en dos clases principales: (a) fitasas ácidas histidinas HAP y (b) fitasas alcalinas.

El género Bacillus produce fitasas alcalinas, es decir actúan a un pH que va de neutro a básico y a una temperatura de $70^{\circ} \mathrm{C}$, lo que le confiere termo-resistencia. La capacidad hidrolítica que posee $B$. subtilis permite la reducción del ácido fítico impidiendo que se presente quelación de los minerales que se encuentran en la biomasa y así se evita que el fósforo y las diferentes trazas de elementos se vuelvan insolubles y se precipiten. En esto radica la importancia de la acción de estas bacterias frente al ciclo del fósforo y su función de beneficio a la biodiversidad de la flora y los suelos. (68)

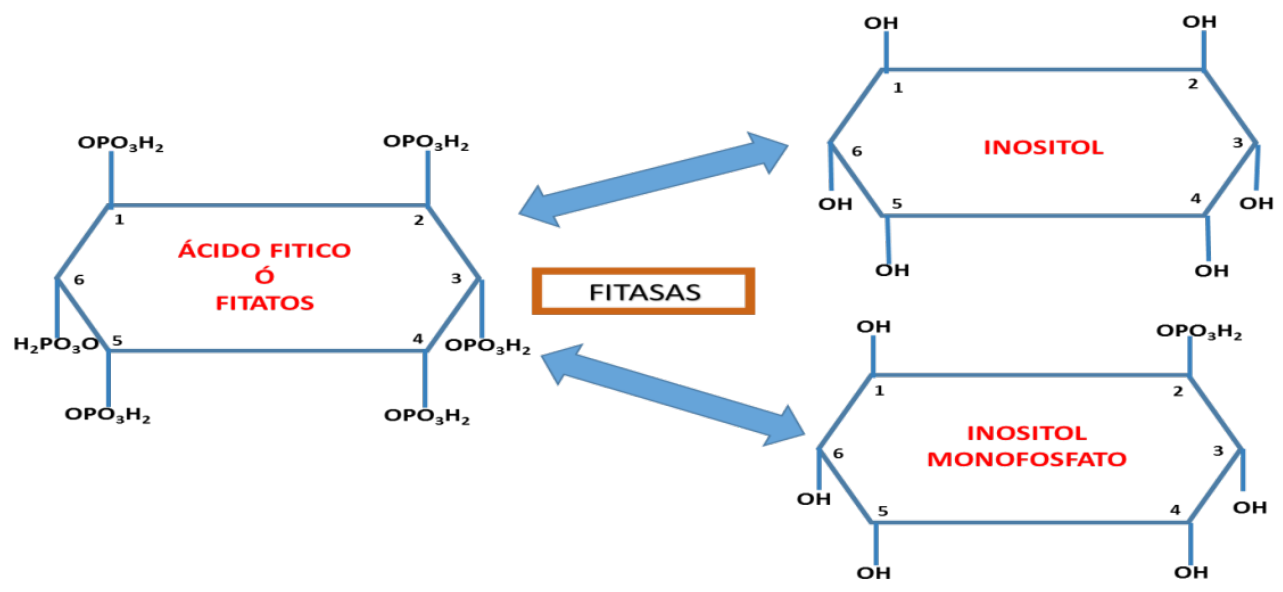

Figura 4. Reacción enzimática de la fitasa sobre el ácido fítico. Fuente: L.C. Corrales, 2016 (69) 
Estudios realizados por Haefner y colaboradores, en 2005, evidenciaron que la equivalencia de fósforo en las fitasas microbianas evaluadas mejoran las concentraciones de $\mathrm{Ca}, \mathrm{Mg}$ y otros metales tales como $\mathrm{Zn}, \mathrm{Cu}, \mathrm{Fe}$ y $\mathrm{Mn}$ por efecto directo o indirecto. La producción de fitato inhibe enzimas proteolíticas que le permiten secuestrar ciertos azúcares, lo que favorece la producción de energía (fotosíntesis) para un óptimo desarrollo de los ciclos biológicos sobre los que influye (68).

Dentro de los compuestos catalizados por las fitasas se ha detectado con mayor proporción el ácido fítico o myo-inositol 1, 2, 3, 4, 5, 6- hexaquis dihidrógeno fosfato (IUPAC and IUPACIUB, 1968; IUPAC-IUB, 1977). Su fórmula química es $\mathrm{C}_{6} \mathrm{H}_{18} \mathrm{O}_{24} \mathrm{P}_{6}$ y presenta una masa mol de $659,86 \mathrm{~g} / \mathrm{mol}$. Se caracteriza por poseer un alto contenido en fósforo, de aproximadamente un $28,2 \%$, se trata de un líquido de color amarillo claro y se encuentra en un mayor porcentaje en el reino vegetal, es soluble en solventes polares e insoluble en solventes no polares; suele aislarse en compañía de las sales de sodio y calcio que le otorgan estabilidad. Se ha descrito que las fitasas mediante hidrólisis pueden remover grupos fosfatos presentes en ácido fitico, convirtiéndolos en myo-inositol, fosfatos y fosfatos orgánicos (66).

Estudios han evidenciado que la interacción entre el fitato y los minerales ponen de manifiesto la existencia de una relación inversamente proporcional en cuanto a la absorción de micronutrientes y el AF, que alteran de manera visible las condiciones físicas y químicas de las plantas. La participación de la enzima fitasa es importante porque cataliza los procesos de desfosforilación de los grupos fosfoéster liberando secuencialmente hasta 6 grupos ortofosfatos libres. Por cambios bioquímicos que actúan a un $\mathrm{pH}$ neutro permiten la movilización de Pi hacia la planta generando reservas de fósforo para el adecuado crecimiento y desarrollo fisiológico (2).

Un gran número de fosfatasas ácidas, de procariotas y eucariotas comparten dos regiones similares, alrededor de un residuo de histidina conservado, la cual participa en procesos de catálisis enzimática actuando de dos formas: la primera se localiza en la sección N-Terminal y forma un intermediario de fosfohistidina; mientras que la segunda se localiza en la sección C-Terminal y posiblemente actúa como donador de protones. La capacidad de producción de fosfatasas, por parte de los microorganismos, sugiere el gran potencial de los mismos para contribuir a la mineralización del $\mathrm{P}$. $(70,71)$.

La reacción de la fitasa, requiere de un intermediario de fosfohistidina en la reacción de transferencia del grupo fosforil catalizándose la hidrólisis como aparece en la Figura 5:

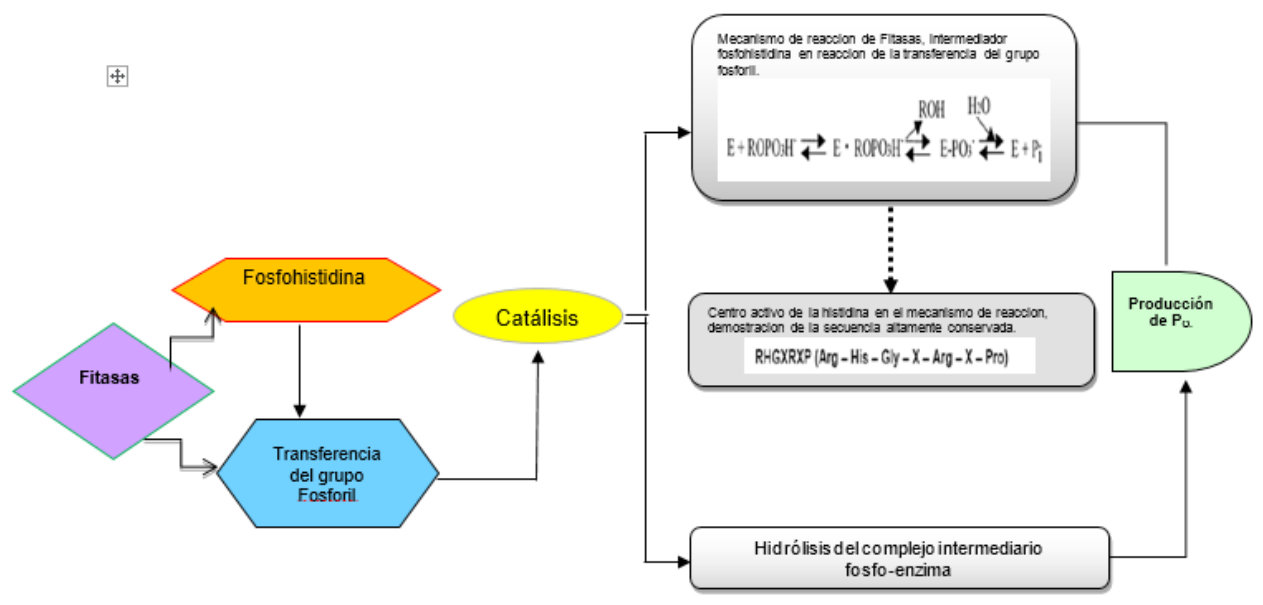

Figura 4. Producción enzimática de Bacillus subtilis frente a la producción de fosforo orgánico. Fuente: M.A Gómez, R.S Ramos, N. Rodríguez. 2016. (72) 


\section{Ácido fítico y cationes}

Investigaciones realizadas en 1987 y 1988 permitieron deducir que las interacciones que se presentan entre el AF y los cationes, conllevan a la formación de una variedad de sales de myo-inositol hexaquisfosfato. Estas sales presentan distintas características dependiendo del tipo de catión que las constituya y del $\mathrm{pH}$ en que se encuentre el ácido fítico .Las sales que se forman a partir de esta interacción se denominan fitatos formándose con cationes de $\mathrm{Na}^{+}, \mathrm{Mg}^{+2}, \mathrm{~K}^{+}, \mathrm{Ca}^{+2}, \mathrm{Zn}^{+2}$, $\mathrm{Cu}^{+1+2}$ y $\mathrm{Fe}^{+2+3}$. La fitina se define a partir de la mezcla de sales de $\mathrm{Ca}$ y $\mathrm{Mg}$ con $\mathrm{AF}$, estas son predominantes en la asociación planta-microorganismo cuando cumple la función de fosfato, myo-inositol y liberación de cationes durante la germinación.

La solubilidad de sales y proteínas está relacionada con el $\mathrm{pH}$, el número de protones y la formación de complejos a partir de sus cargas eléctricas: iones libres de los grupos fosfato $(66,67)$.

En respuesta a la acción enzimática de fosforiladores, se puede decir que en la última década se han incrementado los estudios experimentales sobre el análisis bioquímico y su interacción entre microorganismos y vegetales, evidenciándose el aumento en la concentración del fósforo disponible en formas asimilables y en el proceso continuo de la absorción de otros tipos de nutrientes, los cuales generan una respuesta positiva frente a las características de los suelos y las plantas (2).

\section{Uso de las nitrogenasas y fitasas en la actualidad}

Las nitrogenasas de Bacillus tienen como función principal un interés agronómico y ecológico, aunque su mecanismo de acción no está bien definido, la fijación del nitrógeno significa un aporte fundamental en los ecosistemas naturales que se ven saturados por la aplicación de fertilizantes debido a que estos contaminan los mantos acuíferos, son de altos costos y suelen perderse grandes cantidades de $\mathrm{N}$ por lixiviación (73).
La fijación biológica del nitrógeno mediada por Bacillus mejora la fertilidad del suelo en comparación con la fertilización química y orgánica que genera altos niveles de contaminación con sales nitrogenadas, metales pesados, y microorganismos patógenos para el ser humano y los animales. Especies como B. fusiformis aislados de maíz, trigo y arroz, han sido caracterizados con una elevada actividad nitrogenasa, demostrando su excelente fijación de nitrógeno. Estudios han mostrado que la especie $B$. firmus tiene la capacidad de potenciar la actividad nitrogenasa de microorganismos aislados de otras plantas como Dactylus glomerata, aumentando la cantidad de nitrógeno fijado por la planta, lo cual conlleva a una reducción considerable en el uso de fertilizantes nitrogenados de origen químico (74).

Bacillus cereus se ha usado en consorcio con Rhizobium, permitiendo la formación del nódulo, y aumentando la actividad nitrogenasa para obtener un incremento en la producción de guandul (Cajanus cajan L) (75). Por otro lado, se han realizado co-inoculaciones en cultivos de soya con especies de Azospirillum que aumentan la actividad nitrogenasa, favoreciendo así la fijación del nitrógeno atmosférico (76). Así mismo, el fósforo y la solubilización de éste, también tiene diversas maneras en las que se puede aprovechar mediante el uso de las fitasas; la relación entre la capacidad de solubilización de fosfatos por microorganismos y su influencia positiva en la naturaleza generalmente pasa por diferentes procesos como la producción de ácidos orgánicos, quelación y reacciones de intercambio.

Las fitasas de Bacillus suelen ser usadas como aditivo en los cereales y alimentos de producción animal para mejorar la biodisponibilidad del fosfato y cationes divalentes del fitato (77). Diversos estudios experimentales han mostrado el efecto en la disponibilidad del fósforo y otros nutrientes, en animales como camarones, aves y cerdos que poseen estómagos simples con poca actividad fitasa digestiva. Este tipo de animales 
no son capaces de utilizar el fitato-P y por ende necesitan suplementos alimenticios de fosforo inorgánico, que es costoso y no renovable de tal forma que se mejora su asimilación y aumenta la producción animal, lo cual representa reducción de la contaminación causada por el fósforo. (78). El fitato-P que no es usado en la dieta es excretado y puede causar una fuerte polución en áreas donde se maneja producción intensiva de estos animales (79).

La eutrofización es el proceso de cambio de un estado trófico a otro de nivel superior por adición de nutrientes. La agricultura es uno de los factores principales de eutrofización de las aguas superficiales. En cuanto a la acuicultura, los costos de alimentación representan aproximadamente el $70 \%$ del costo total de producción, los peces no pueden utilizar el fósforo de la fitina que provee el alimento por lo cual este es excretado en el agua siendo un foco de contaminación; por otro lado, las fitasas bacterianas son un excelente medio para favorecer la asimilación del fósforo y mantener los niveles de éste aceptables en el agua (80).

Las fitasas tienen la capacidad de mejorar la biodisponibilidad de minerales y oligoelementos al ser adicionadas en el proceso de elaboración de los alimentos, ya que impactan positivamente el proceso de producción, el rendimiento y la calidad final del producto (81). En la producción de alimentos a base de plantas, la introducción de una fitasa exógena representa un aumento considerable en la cantidad de proteínas, mejora la biodisponibilidad mineral, su composición de aminoácidos, y la digestibilidad in vitro de la proteína; por lo cual es muy usada en formulaciones de alimentos para niños (82).

La adición de fitasas junto con otras enzimas que degradan la pared celular vegetal en el proceso de maceración en la molienda del maíz facilita la obtención del licor de maíz, suaviza el grano, mejora el rendimiento del almidón y la separación del gluten y la fibra; así como facilita la reducción en los tiempos de remojo en la molienda. El licor de maíz libre de fitato, es muy usado en la industria de la fermentación para la producción de compuestos enzimáticos, levadura, polisacáridos, antibióticos y aminoácidos como ingrediente en alimentos para animales $(83,84)$.

En la nutrición humana, las fitasas han sido empleadas para mejorar la calidad nutricional de los alimentos y hacerlos funcionales. Estas enzimas comienzan la defosforilación del myo-inositol en las posiciones 3 y 6 respectivamente. La 3-fitasa se encuentra en animales y microorganismos mientras la 6-fitasa está presente en vegetales. La aplicación de fitasas exógenas como las de Bacillus spp., durante el procesamiento de alimentos como cereales y leguminosas mejora la hidrólisis del ácido fítico permitiendo una mayor asimilación de éste y así reducir el riesgo de padecer déficit de minerales en la nutrición (85).

Desde el punto de vista genético, la expresión de fitasas inducida en bacterias, es regulada y se utiliza para desarrollar nuevas estrategias en la solubilización del fósforo en el suelo, siempre y cuando exista una disponibilidad de Pi y Po (86).

Se observa un aumento considerable a escala mundial de la inclusión de estas enzimas en la producción de bioinsumos como productos que favorecen la agricultura sostenible y brindan alternativas emergentes a la sostenibilidad de las necesidades del campo. Un bioinsumo está constituido por abono orgánico natural, micorrizas, feromonas, parasitoides, extractos de plantas y entomopatógenos, los cuales ayudan a que los sistemas agrícolas se recuperen más rápidamente para volverse a cultivar, son menos costosos que los productos químicos, son de alta especificidad y actualmente, se ha encontrado mayor efectividad con el uso de bacterias como Bacillus thuringiensis y hongos como Metarhizium anisopliae y Beauveria bassiana. Por otro lado, a nivel de productividad en las industrias agrícolas, tene- 
mos que la soya en Suramérica, en su mayoría es fertilizada con inoculantes de alta calidad, producidos a partir de Bradyrhizobium japonicum (87) y en México, gran parte de los cultivos de maíz son biofertilizados con la bacteria fijadora de nitrógeno Azospirillum brasilense (88).

\section{Biofertilizantes}

Los biofertilizantes mejoran la disponibilidad de nutrientes a los cultivos, y conservan el suelo desde su diversa función biológica. La importancia de los microorganismos y su relación con el ambiente se ha ido enfocando actualmente en la necesidad de aprovechar la versatilidad benéfica de ciertos agentes biológicos a la agricultura y a favorecer la interacción fitoestimulante, al suministro de nutrientes por acción de los ciclos biogeoquímicos, al mejoramiento de la estructura con formación de agregados estables, a la función del control biológico, eliminación de productos xenobióticos y al mejoramiento ecofisiológico, mediante el incremento de la resistencia de las plantas al estrés tanto biótico como abiótico (89).

La actividad de los biofertilizantes se centra en los diferentes ciclos biológicos dado que por medio de reacciones enzimáticas se sintetizan, solubilizan o fijan los diferentes elementos químicos, donde pueden generar dos tipos de reacciones: la primera es la síntesis de nuevas sustancias benéficas frente a la restauración, por la producción de sustancias antagónicas frente a patógenos y la segunda, se centra en la promoción de crecimiento vegetal (90).

El manejo de los inoculantes debe ser analizado previamente teniendo en cuenta la deficiencia de nutrientes, la fluctuación de crecimiento de los microorganismos nativos, su capacidad de colonización, síntesis de sustancias que promueven el crecimiento de la planta, fijación del nitrógeno atmosférico, solubilización del hierro, fósforo inorgánico y mejoramiento de la tolerancia al estrés exógeno natural o inducido (91).
Aunque en muchos países desarrollados se manejen tecnologías muy avanzadas y novedosas para producir estos inoculantes hay cierta renuencia para su aplicación en áreas rurales debido a que han sido asociados con enfermedades en humanos y animales; muchos de estos agentes biológicos (Bacillus spp, Pseudomonas spp., Trichoderma spp., Rhizobium spp., Azotobacter spp., Azospirillum spp, etc.)

El género Bacillus ha sido estudiado por poseer una variedad de mecanismos, entre ellos la fijación biológica del nitrógeno y la solubilización de fosfatos, que ha impulsado diferentes estudios en el sector agrícola que buscan la disminución, y en el mejor de los casos, la erradicación de los fertilizantes químicos, acción que representaría un impacto positivo sobre el medio ambiente Sumado a estos beneficios se destaca la capacidad de degradación de sustratos de plantas y animales, la producción de antibióticos, la capacidad de sobrevivir en múltiples condiciones ambientales y la actividad antagónica e inhibidora entre otras, pone al género Bacillus en un lugar destacado para su uso en la agricultura sostenible (9295).

\section{Conclusiones}

Los fertilizantes químicos solubles, de acción lenta y con propiedades quelantes generan grandes cantidades de compuestos y elementos que no pueden ser usados por las plantas y que tienden a bioacumularse, contaminando con sustancias tóxicas al suelo, las cuales afectan la microbiota y biomasa en general.

De acuerdo con la literatura consultada el género Bacillus se reporta más con capacidad solubilizadora de fosfato y muy poco con la fijación de nitrógeno.

El género Bacillus presenta diversas características y versatilidad para su aplicación, haciéndolo un excelente candidato en el mejoramiento de la disponibilidad de nutrientes para las plantas y para la recuperación de suelos. 
Los suelos agrícolas tienen cantidades de fosfatos insolubles que solo pueden ser aprovechados por las plantas mediante la acción enzimática microbiana. Las fitasas, producidas por Bacillus desempeñan un papel muy importante en la nutrición de las plantas mejorando la disponibilidad de fósforo, por lo que son usadas como biofertilizantes.

Existen muchas referencias en relación con la capacidad de fijación de nitrógeno por microorganismos; sin embargo, no hay suficientes fuentes que describan el mecanismo de acción de las nitrogenasas del género Bacillus. Se encuentran reportes que clasifican este género bacteriano como fijador de nitrógeno junto a otros microorganismos formando consorcios y demostrando que tienen actividad nitrogenasa, lo cual se ha demostrado en medios selectivos.

Las especies del género Bacillus y el potencial de sus enzimas amplían las perspectivas de uso para una agricultura sostenible, lo que permite la conservación del medio ambiente y un mejoramiento de la calidad y la producción en cultivos de interés agrícola. Lo anterior, a su vez, genera excelentes resultados y reduce su impacto en la saturación de los suelos, costos en la producción y contaminación al medio ambiente.

Mediante esta revisión se evidencia que el género Bacillus spp. es un agente biofertilizante que ha sido estudiado en las ultimas 5 décadas con un crecimiento significativo, relacionado con las actividades físico-químicas de las enzimas nitrogenadoras y fosforiladoras que contribuyen a la promoción de crecimiento vegetal.

El uso de fertilizantes biológicos, favorece el desarrollo de asociaciones de micorrizas incrementando la disponibilidad del fósforo, y brindando un suministro continúo de micronutrientes al suelo; por tanto, reduciendo el desarrollo de ciertas enfermedades en las plantas. También contribuye al mantenimiento de concentraciones de nitrógeno y fósforo disponibles, minimizando la lixiviación e incrementando la retención de agua.

Debido a la riqueza genética de los ecosistemas del trópico, el uso de la biodiversidad vegetal y/o microbiana es una apuesta natural para resolver la necesidad de producción de alimento de tipo vegetal y así contribuir a erradicar el hambre y mantener los ecosistemas.

\section{Referencias}

1. ONU. Organización de las Naciones Unidas [internet]. ONU, (septiembre de 2015; citado 27 de febrero de 2017). Disponible en: http.www.un.org. Recuperado el 27 de febrero de 2017 de http://www.un.org/sustainabledevelopment/es/ hunger/.

2. Corrales LC, Arévalo ZY. Moreno VE. Solubilización de fosfatos: una función microbiana importante en el desarrollo vegetal. NOVA. 2014; 12(21):67-79.

3. Jiménez D. Caracterización de cepas nativas Colombianas de Azotobacter spp. mediante el análisis de restricción del DNA ribosomal 16s. Pontificia Universidad Javeriana. Facultad de Ciencias Básicas, Microbiología Industrial. [Internet]. 2007 [citado febrero 23 de 2016.] Disponible en: http://www.javeriana.edu.co/biblos/tesis/ciencias/tesis14.pdf

4. Flores A, Rodríguez R, Contreras J. La fijación biológica de nitrógeno por microorganismos; su importancia en la agricultura y conservación del medio ambiente. Rev Ciencia cierta, [Internet] 2009. [citado enero 2016]; 5(19). Disponible en http: //www.posgradoeinvestigacion.uadec.mx/cienciacierta/ CC19

5. ICA.2004. Uso de microorganismos con potencial como biofertilizante en el cultivo de mora. Ministerio de Agricultura y Desarrollo rural. Instituto Colombiano Agropecuario ICA. Bogotá.

6. Urzúa H, Beneficios de la Fijación Simbiótica de Nitrógeno en Chile. Cien. Inv. Agr. [Internet]. 2005 [citado 25 de febrero de 2016]; 32(2):133-150. Disponible en: https://www. google.com.co/?gfe_rd=cr\&ei=8qjRWIKYF6XI8AeE5q-AD$\mathrm{w} \# \mathrm{q}=\mathrm{Urz} \% \mathrm{C} 3 \% \mathrm{BAa}+\mathrm{Y} .+$ Beneficios $+\mathrm{de}+\mathrm{la}+\mathrm{Fijaci} \% \mathrm{C} 3 \% \mathrm{~B}-$ $3 n+$ Simbi $\%$ C3\%B3tica+de+Nitr $\%$ C3\%B3geno+en+Chile.+Cien.+Inv.+Agr.+2005;+32(2):+133-150.\&* .

7. Fernández MT, Rodriguez H. El papel de la solubilización de fosforo en los biofertilizantes microbianos. ICIDCA [Internet]. 2005 [citado 14 enero 2016]; 39 (3): 27-34. Disponible en: http//www.redalyc.org/articulo.oa?id-223120688005

8. Cuervo J. Aislamiento y Caracterización de Bacillus spp como fijadores biológicos de Nitrógeno y Solubilizadores de fosfatos en dos muestras de biofertilizantes comerciales. Pontificia Universidad Javeriana. Microbiología agrícola y veterinaria [Internet]. 2010 [citado 23 de febrero de 2016]. Disponible en: http://www.javeriana.edu.co/biblos/tesis/ciencias/tesis404.pdf 
9. Portela D., Chaparro A, López S. La biotecnología de Bacillus thuringiensis en la agricultura. NOVA. 2013; 11: 87-96.

10. Wagner SC. Biological Nitrogen Fixation. Nature Education Knowledge 2012; 3(10):15.

11. Validation of the Publication of New Names and New Combinations. Previously Effectively Published Outside the IJSB. List no. 51. International Journal of Systematic Bacteriology. 1994; 45(1): 625-626.

12. Jones DH. Further studies on the growth of Azotobacter. Journal of Bacteriology, 1920; 5(4): 325-341.

13. Postgate, J.R. The fundamentals of nitrogen fixation. Press syndicate of the University of Cambridge. Cambridge-England. Library of congress catalogue card number, 1982.

14. Pérez, G. Fijación Simbiótica de Nitrógeno: estado actual y perspectivas. Rev. Acad. 1990; (17): 477-487.

15. Seldin J. D. Van Elsas, E. G. C. Penido. Bacillus azotofixans. nov. a Nitrogen-Fixing Species from Brazilian Soils and Grass Roots. International Journal of Systematic Bacteriology. 1984; $4(34): 451-456$.

16. Ibarra C. L. Diversidad de bacterias fijadoras de nitrógeno aisladas de suelo de Chinampa y su efecto en plantas de interés agrícola. [Tesis]. Escuela nacional de ciencias biológicas, sección de estudios de posgrado e investigación, Departamento de Microbiología. México, 2010.

17. M. J. Merrick and R. A. Edwards. Nitrogen Control in Bacteria. Microbiological Reviews. 1995; 54: 604-622.

18. Xie G, Su B, Cui Z. Isolation and identification of N2-fixing strains of Bacillus in rice rhizosphere of the Yangtze River Valley. Department of Agronomy, China Agricultural University. [Internet] 1998. [Citado marzo de 2014]. Disponible en: http://www.ncbi.nl.nih.gov/pubmed/12548929.

19. Fisher S. Regulation of nitrogen metabolism in Bacillus subtilis: vive la difference. Molecular Microbiology. 1999; 32 (2): 223-232.

20. Orozco J. C, Martínez P. Evaluación de la inoculación con microorganismos fijadores de nitrógeno asimbióticos aislados de la rizosfera de Pinus patula en Colombia. Instituto de Investigaciones Biológicas Alexander von Humboldt, Estación Forestal La Florida, Cota. 2009; BOSQUE 30(2): 70-77.

21. Orhan, E, Esitken A, Ercisli S, Turan M, Sahin, F. Effects of plant growth promoting rhizobacteria (PGPR) on yield, growth and nutrient contents in organically growing raspberry. Sci. Hort. 2006; 111: 38-43.

22. Kloepper JW, Ryu CM, Zhang S, Induced systemic resistance and promotion of plant growth by Bacillus spp. Phytopathology. 2004. 94: 1259-1266.

23. Beneduzi A, Pérez D, Beschoren P, Bodanese Z. B, Pereira P. L, et al. Genetic and phenotypic diversity of plant-growth-promoting bacilli isolated from wheat fields in southern Brazil. Res Microbiol. 2008; 159: 244-250.

24. A.J. Acuña, G.N. Pucci, O.H. Pucci. Caracterización de tres cepas bacterianas capaces de fijar nitrógeno y biodegradar hi- drocarburos aisladas de un suelo de la Patagonia. Revista Ecosistemas. 2010; 19: 125-136.

25. Sanyal, S. K. y De Data, S. K. Chemistry of phosphorus transformation in soil. Adv Soil Sci. 1991; 16: 1-120.

26. Richardson, A. E. Soil microorganisms and phosphorous availability. In Soil biota: management in sustainable farming systems. Victoria-Australia: Eds. C E Pankhurst, B M Doube; 1994.

27. Shin, S., HA, N., OH, B., OH, T., OH, B., Enzyme Mechanism and Catalytic Property of Propeller Phytase. Structure, 2001; 9: 851-858.

28. Wakelin, S. A.; Warren, R. A.; Harvey, P. R. and Ryder, M. H. Phosphate solubilization by Penicillium spp. closely associated with wheat roots. Biol. Fert. Soils. 2004; Cap. 40: 36-43.

29. Fernández, M. T., \& Rodríguez, H. El papel de la solubilización de fósforo en los biofertilizantes microbianos. ICIDCA. 2005; 39: 27-34.

30. Oberson, A. and Joner, E. Microbial turnover of phosphorus in soil. In: B. L. Turner, E. Frossard and D. S. Baldwin (Editors). Organic phosphorus in the environment. CAB International. 2005; Cap. 7: 133-160.

31. Rodríguez H, Rubiano ME. Aislamiento e identificación de hongos solubilizadores de fosfatos aislados de cultivos de arroz y evaluación del $\mathrm{pH}$ y concentraciones de sacarosa y cloruro de sodio sobre su actividad solubilizadora [Tesis de Grado] Pontificia Universidad Javeriana. Bogotá Colombia, 2002.

32. Khan, M. S.; Zaidi, A. and Wani, P. Role of phosphate-solubilizing microorganisms in sustainable agriculture - a review. Agron. Sustain. Dev. 2007. Ch. 27, pp. 29-43.

33. Zaidi, A.; Khan, M. S.; Ahemad, M.; Oves, M. and Wani, P. A. (Editors). Recent advances in plant growth promotion by phosphate-solubilizing microbes. En: Mohammad Saghir Khan; Almas Zaidi and Javed Musarrat (Editors). Microbial strategies for crop improvement. Springer-Verlag, Berlin. 2009. 23-50.

34. Patińo C. Solubilización de fosfatos por poblaciones bacterianas aisladas de un suelo del Valle del Cauca: estudio de biodiversidad y eficiencia. [Trabajo de Grado], Universidad Nacional de Colombia. Palmira. Colombia, 2010.

35. Greaves, M. P., Anderson, G., y Webley, D. M. The hydrolysis of inositol phosphates by Aerobacter aerogenes. Biochim. Biophys. 1968; Acta.132: 412-418.

36. Irving, G. C. J. y Cosgrove, D. J. Inositol phosphate phosphatases of microbiological origin. Some properties of a partially purified bacterial (Pseudomonas sp.) phytase. Aust. J. Biol. Sci. 1971; 24: 547-557.

37. Powar, V. K Jagannathan, V. Phytase from Bacillus subtilis. Indian J. Biochem. 1967; Ch. 4: 184-185.

38. Greiner, R., Konitzny, U., Jany, K. D. Purification and characterization of two phytases from Escherchia coli. Arch. Biochem. Biophys. 1993; 303: 107-113.

39. Shieh, T.R, y Ware J.H. Survey of Microorganisms for the Pro- 
duction of Extracellular Phytase, Applied Microbiology. 1968; Cap. 16: 1348-1351.

40. Rojas, F. A. V. Producción a Nivel Pre-piloto de Enzima Fitasa de Aspergillus Ficuum, Utilizando Sistemas de Fermentación en Estado Líquido y Sólido. [Tesis de grado. Universidad Austral de Chile. Valdivia. Chile. 2009.

41. Richardson, A. E. y otros. Utilization of phosphorus by pasture plants supplied with myo-inositol hexaphosphate is enhanced by the presence of soil microorganisms. Plant and Soil, 2001; (229): 47-56.

42. Cuadrado, B. Rubio G, y Santos W. (2009) Caracterización de cepas de Rhizobium y Bradyrhizobium (con habilidad de nodulación) seleccionados de los cultivos de fríjol caupi (Vigna unguiculata) como potenciales bioinóculos. En Revista Colombiana de Ciencias Químico-Farmacéuticas, Vol. 38, Núm 1. P. Consultado en: http://www.revistas.unal.edu.co/index. $\mathrm{php} / \mathrm{rccquifa/rt/printerFriendly/15432/36602. \quad Consultado}$ marzo 14 de 2017

43. Palma F. J. obtención de un extracto de fitasa con actividad a baja temperatura, mediante fermentación en sustrato sólido. (Tesis de grado). Universidad Austral de Chile. Valdivia-Chile, 2007.

44. Corrales L. C., Sánchez L. C., Arévalo Z. Y., Moreno V. E., Bacillus: género bacteriano que demuestra ser un importante solubilizador de fosfato. NOVA. 2014; 12(21): 165-178

45. Figueroa M. J. Fijación biológica del nitrógeno. Revista UDO Agricola 2004; 4(1): 105 - 107

46. Corrales. L.C., (2016). Figura: Ciclo del Nitrógeno. Adaptada de: https://www.google.com.co/webhp?sourceid=chrome-ins$\operatorname{tant} \&$ ion $=1 \&$ espv=2\&ie $=U T F-8 \# \mathrm{q}=\mathrm{ciclo}+\mathrm{del}+$ nitr\%C3\%B3geno\&*. Consultada: Noviembre 15 de 2016.

47. Rowell, D.L. Soil Science Methods \& Applications. Department of Soil Science, 1994. University of Reading

48. Menezes A. Aislamiento y caracterización de bacterias diazotrofas asociadas a maíz (Zea mays) variedad PAU 871". [Trabajo de Grado]. Laboratorio de Microbiología, Facultad de Agronomía. UDELAR, Montevideo, Uruguay, 2009.

49. Corrales. L.C., (2016). Figura: Transformaciones del nitrógeno en el suelo. Adaptada: https://www.google.com.co/ search?q=transformaciones + del + nitrogeno+en + el + suelo\&es$\mathrm{pv}=2 \&$ site $=$ webhp \&source $=\ln \mathrm{ms} \& \mathrm{tbm}=\mathrm{isch} \& \mathrm{sa}=\mathrm{X} \& \mathrm{ve}-$ d=0ahUKEwij86qHitvSAhUJ7SYKHeLUCCEQ_AUIBi$\mathrm{gB} \& \mathrm{biw}=1270 \& \mathrm{bih}=719$ \#imgrc=T6Dk7_qKUCEA5M. Consultada: Noviembre 16 de 2016.

50. Pointillart A. (1994) INRA. Prod. Anim. 7(1): 29-39.

51. Perez E. Carril U. Fotosíntesis: Aspectos Básicos. Serie Fisiología Vegetal. 2009; 2(3): 1-47.

52. Kass D. Fertilidad de Suelos. Primera Edición. San José, Costa Rica. Editorial UNED, 1996.

53. Condron, L; Turner, B; Cade-Menun, B.. Chemistry and dynamics of soil organic phosphorus. In J.T. Sims T, and A.N Sharpley (eds.), Phosphorus. Agriculture and the Environment. American Society of Agronomy Monograph American
Society of Agronomy. 2005; 46: 87-122.

54. Quiquampoix, H., Mousain, D. Enzymatic hydrolysis of organic phosphorus. In: Turner BL, Frossard E, Baldwin DS, editors. Organic phosphorus in the Environment. Wallingford, 2005. ¿cap? ¿páginas?

55. Sanchez. D. Efecto de la inoculación con bacterias promotoras de crecimiento vegetal sobre el cultivo de tomate (Solanum Lycopersicum Var. Sofía) bajo invernadero. Trabajo de Grado Maestría en Ciencias Biológicas. Facultad de Ciencias. Pontifica Universidad Javeriana. Bogotá. 2011.

56. Benjamin L. Turner, Michael J. Papházy, Philip M. Haygarth, Ian D. Mckelvie. Inositol Phosphates. Biologycal Sciences. 2002; 357:1420.

57. Terry E, Leyva A, Hernàndez A. (2005). Beneficios de los Microorganismos como biofertilizantes eficientes para el cultivo de tomate (Lycopersicon esculentum, Mill). Revista Colombiana de Biotecnología. 2005; 7 (7): 47-54.

58. Corrales, L. (2016). Figura: Ciclo del fósforo. Adaptada de: https://www.google.com/search?q=ciclo+del+f\%C3\%B3sforo\&client $=$ firefox $-\mathrm{b}-\mathrm{ab} \&$ source $=\ln \mathrm{m} \& \mathrm{t} \mathrm{tbm}=\mathrm{isch} \& \mathrm{sa}=\mathrm{X} \& v e-$ $\mathrm{d}=0$ ahUKEwjunMbMl9vSAhXHwlQKHUFcDckQ_AUIC$\mathrm{CgB} \&$ biw $=1440 \&$ bih=760. Consultada: Noviembre 20 de 2016.

59. Manangi MK, Coon CN. Phytase phosphorus hydrolysis in broilers in response to dietary phytase, calcium and phosphorus concentrations. Poult Sci, 2008; 87(8): 1577-1586.

60. Corrales, L. C., Sánchez, L. C., Cuervo, J., Joya, J. A. \& Marquez, K. (2012). Efecto biocontrolador de Bacillus spp., frente a Fusarium sp. bajo condiciones de invernadero en plantas de tomillo (Thymus vulgaris L.). NOVA, 10(17):64 - 82.

61. Restrepo-Franco Gloria María, Marulanda-Moreno Sandra, de la Fe-Pérez Yeised, Díaz-de la Osa Acela, Baldani Vera Lucia, Hernández-Rodríguez Annia. Bacterias solubilizadoras de fosfato y sus potencialidades de uso en la promoción del crecimiento de cultivos de importancia económica. Revista CENIC 2015; 46(1): 63-76.

62. Cortés A, García J, Pedroza A. M., Martínez M \& Gutiérrez V. Diseńo de un medio para la producción de un co-cultivo de bacterias fosfato solubilizadoras con actividad fosfatasa. Universitas Scientiarum, 2012; 17(1): 43-52.

63. Banerjee A, Yuhas BD, Margulies EA, Zhang Y, Shim Y, Wasielewski MR, Kanatzidis MG. Photochemical nitrogen conversion to ammonia in ambient conditions with FeMoS-chalcogels. J Am Chem Soc. 2015; 11-137(5):2030- 2034.

64. Chan, Michael K.; Jongsun, Kim Rees, D. C., The Nitrogenase FeMo-Cofactor and P--Cluster Pair: 2.2 A Resolution Structures, Science, 1993; 260: 792-794.

65. Marcia Costa, Gerhard Lerchundi, Francisco Villarroel, Marcelo Torres, Renate Schöbitz. Producción de enzima fitasa de Aspergillus ficuum con residuos agroindustriales en fermentación sumergida y sobre sustrato sólido. Rev. colomb. Biotecnol. 2009;11(1): 73-83.

66. Ríos Vega Milena P. Efecto de dos temperaturas y dos agitacio- 
nes diarias en la producción de fitasa de Aspergillus ficuum por fermentación en estado sólido. [Tesis de grado]. 2008. Universidad Austral de Chile. Valdivia. Chile.

67. Nolan, K.B., Duffin, P.A. y McWeeny, D.J. Effects of phytate on mineral bioavailability. In vitro studies on $\mathrm{Mg}, \mathrm{Ca}, \mathrm{Fe}, \mathrm{Cu}$, $\mathrm{Zn}$, Cd. Solubilities in presence of phytate. J. Sci. Food Agric, 1987; 40: 79 -85.

68. Haefner S., Knietsch A., Scholten E., Braun J., Lohscheidt M., Zelder O. Biotechnological production and applications of phytases. Appl Microbiol Biotechnol, 2005; 68: 588-597.

69. Corrales., L. C (2016) Figura: Reacción enzimática de la fitasa sobre el ácido fítico. Adaptada de: https://www.google. $\mathrm{com} /$ search?q=produccion+de+inositol+a+partir+del+acido+fitico\&client=firefoxbb\&noj=1 \&source $=\operatorname{lnm} s \& \mathrm{tbm}=\mathrm{isch} \&-$ $\mathrm{sa}=\mathrm{X} \& \mathrm{ved}=0 \mathrm{ahUKEwja62HntvSAhXrsFQKHc8xAGQQ}$ AUICCgB\&biw=1440\&bih=760\#imgrc=0xndtjz1F38kJM. Consultada: Noviembre 22 de 2016.

70. Park SC, Choi YW, Oh TK. Actividad enzimática de diferentes fitasas en función del pH. Journal of Veterinary Medical Science. 1999; 61 (11): 1257-1259.

71. Y. Gómez-Guiñán. Actividad de las fosfatasas ácidas y alcalinas (extracelulares e intracelulares) en hongos de la rizosfera de Arachis hypogaea (Papiloneaceae). Rev. biol. Trop. 2004; 52 (1): 287-295.

72. M.A Gómez, R.S Ramos, N. Rodríguez (2016). Figura: Producción enzimática de Bacillus subtilis frente a la producción de fosforo orgánico. Adaptada de: https://www.google.com. $\mathrm{co} /$ search? $\mathrm{q}=$ mecanismos + de + reaccion + de + las + fitasas\&esp$\mathrm{v}=2 \&$ source $=\operatorname{lnm} \& \& \mathrm{tbm}=\mathrm{isch} \& \mathrm{sa}=\mathrm{X} \& \mathrm{ved}=0$ ahUKEwiemY_ Kqf7SAhXGMyYKHS3mAkAQ_AUIBigB\&biw=1440\&$\mathrm{bih}=794 \#$ imgdii $=7 \mathrm{nLWSXeq} 53$ up $6 \mathrm{M}: \& \mathrm{imgrc}=\mathrm{vZ}$ q746U48ndQNM:. Consultada: Diciembre 10 de 2016.

73. Morot-Gaudry, J.F. Nitrogen assimilation by plants. Physiological, biochemical and molecular aspects. Science Publisher Inc. Plymouth, RU, 2001.

74. Zlotnikov A, Shapovalov Y, Makarov A. Association of Bacillus firmus E3 and Klebsiella terrigena E6 with increased ability for nitrogen fixation. Soil Biology and Biochemistry, 2001;33 (11): 1525-1530.

75. Tilak K, Ranganayaki N, Manoharachari C. Synergistic effects of plant-growth promoting rhizobacteria and Rhizobium on nodulation and nitrogen fixation by pigeonpea (Cajanus cajan L.). European Journal of Soil Science, 2006.

76. Fernández-Pascual M, Casas MA, Rubio C, Roldos J, Jerez F, Guach L, et al. Intercroping of coinoculated soybean and sugarcane productivity. Current Plant Science and Biotechnology in Agriculture, 2002.

77. Guerrero Olazarán, M., Rodríguez Blanco, L., \& Viader Salvadó, J. M. Producción de una fitasa recombinante en Pichia pastoris. Ciencia UANL, 2007; 10(4): 413-418

78. Ruijuan Li, Jinfeng Zhao, Chuanfan Sun, Wenjing Lu, Chengjin Guo, Kai Xiao. Biochemical properties, molecular characterizations, functions, and application perspectives of phytases. Frontiers of Agriculture in China. 2010; 4 (2):195-209.
79. Sweeten JM. Livestock and poultry waste management: a national overview. In: Blake JD, Magette W (eds) National livestock, poultry and aquaculture waste management. Amer Soc Agric Eng, St. Joseph, Minnesota, 1991; 195-209.

80. X.G. Lei, C.H. Stahl, Biotechnological development of effective phytases for mineral nutrition and environmental protection. Appl Microbiol Biotechnol. 2001; 57: 474-481.

81. M. Wang, N.S. Hettiarachchy, M. Qi, W. Burks, T. Siebenmorgen, Preparation and functional properties of rice bran protein isolate, J. Agric. Food Chem, 1999; 47(2):411-416.

82. M. Fredrikson, P. Biot, M. Larsson Alminger, N.G. Carlsson, A.S. Sandberg, Production process for high-quality pea-protein isolate with low content of oligosaccharides and phytate, J. Agric. Food Chem, 2001; (49) 3: 1208-1212.

83. N. Singh', and S. R Eckhoff. Wet Milling of Corn-A Review of Laboratory-Scale and Pilot Plant-Scale Procedures. Cereal Chem. 1996. 73(6): 659-667.

84. R.L. Antrim, C. Mitchinson, L.P. Solheim, Method for liquefying starch. US patent 5652127, 1997.

85. Frontela, C., Ros, G., \& Martínez, C. Empleo de fitasas como ingrediente funcional en alimentos. Sociedad Latinoamericana de nutrición. 2008. 58(3):215-220.

86. Sánchez-López DB, Gómez-Vargas RM, Garrido-Rubiano MF, Bonilla-Buitrago RR. Inoculación con bacterias promotoras de crecimiento vegetal en tomate bajo condiciones de invernadero. Rev. Mex. Cienc. Agríc, 2012. 3.(7): 1401-1415

87. Shiri-Janagard, M.; Raei, Y.; Gasemi-Golezani, K.; Aliasgarzard, N. Influence of Bradyrhizobium japonicum and phosphate solubilizing bacteria on soybean yield at different levels of nitrogen and phosphorus. Intl. J. Agron. Plant. Prod. 2012; 3(11): 544-549.

88. García-Olivares, J.G.; Mendoza-Herrera, A.; Mayek-Perez, N. Efecto de Azospirillum brasilense en el rendimiento del maíz en el norte de Tamaulipas, México. Universidad y Ciencia. 2012. 28(1):79-84.

89. Zambrano D, -Moreno, L F Rodríguez R, Van Strahlen M, Bonilla R. Industria de bioinsumos de uso agrícola en Colombia. rev.udcaactual.divulg.cient. 2015; 18 (1): 59-67.

90. Arath O, Cabrera G, Díaz A. ET AL., Impacto de los biofertilizantes en la agricultura. Campo Experimental Bajío. INIFAP. Rev. Mex. Cienc. Agríc. 2012; 3(6): 1261-1274.

91. Elliott, L. F. and Lynch, J. M. The international workshop on establishment of microbial inoculant in soils: Cooperative research project on biological resource management of the Organization for Economic Cooperation and Development (OECD). Am. J. Alt. Agric, 1995.

92. Tejera-Hernández B., Rojas-Badía M.M., Heydrich-Pérez M. Potencialidades del género Bacillus en la promoción del crecimiento y el control biológico de hongos fitopatógenos. Revista CNIC 2011; 42(3): 131-138

93. Ramírez, L. C. C., et al. Solubilización de fosfatos: una función microbiana importante en el desarrollo vegetal. Nova. 2014; 12(21) 
94. Galvez, Z. Y. A. and V. E. M. Burbano. Bacillus: género bacteriano que demuestra ser un importante solubilizador de fosfato. NOVA Publicación en Ciencias Biomédicas. 2015; 12(22): 165-177.

95. Rodríguez, O. E., Andrade, W. A., Díaz, F. E., \& Moncada, B. Actividad antimicrobiana de líquenes de la cuenca alta del rio Bogotá. 2015; Nova, 13(23). 